\title{
Cell Proliferation Assay
}

National Cancer Institute

\section{Source}

National Cancer Institute. Cell Proliferation Assay. NCI Thesaurus. Code C116553.

Any method to measure the number of dividing cells in a culture, or to measure the change in the proportion of cells that are dividing. 